\title{
Enhanced prostanoid release from monocytes of patients with rheumatoid arthritis and active systemic lupus erythematosus
}

\author{
M SEITZ AND W HUNSTEIN
}

From the University of Heidelberg, Medical School (Medizinische Poliklinik), Heidelberg, West Germany

SUMMARY In patients with rheumatoid arthritis high levels of prostaglandin $E_{1}$ have been found in the joint fluid, and its increased production by adherent synovial cells and macrophages clearly supports the notion that this arachidonic acid metabolite is involved in the pathology of the disease. Besides its known inflammatory qualities and the suppressive effects on various lymphocyte functions prostaglandin $\mathrm{E}_{2}$ has proved to be an essential cofactor in the secretion of the lymphokine osteoclast activating factor.

In this study we have discovered an enhanced release of prostaglandin $E_{1}$ and thromboxane $B_{2}$ from a subpopulation of blood monocytes from patients with rheumatoid arthritis and active systemic lupus erythematosus.

No correlation between prostanoid release from monocytes and inflammatory activity of the disease was found. However, even monocytes from patients with early stage or mild inflammatory activity displayed a 'stimulated' arachidonic acid metabolism.

In contrast only patients with active systemic lupus erythematosus showed in this respect comparable secretory activity or monocytes.

Our findings may point to a possible pathogenic role of prostanoids in rheumatoid arthritis, which may also have some implication for the early diagnosis of this disease and for its differentiation from other chronic inflammatory rheumatic conditions.

In rheumatoid arthritis (RA) cells originating from the monocyte-macrophage lineage are considered to play an important part in the course of chronic inflammation $^{1-5}$ and joint destruction. This is mediated by degradative lysosomal enzymes, collagenase, complement factors, ${ }^{6-8}$ and an increased release of mediators such as prostaglandin $E_{2}$ and interleukin 1. ${ }^{9-14}$ Moreover the function of blood monocytes, the supposed precursors of type A synovial cells, seems to be altered in RA patients. On the one hand a reduced in-vivo clearance of particles and immune complexes has been reported, ${ }^{15}$ a decreased $\mathrm{C} 3 \mathrm{~b}$ receptor-mediated phagocytosis, ${ }^{16}$ and a decreased bactericidal function. ${ }^{17}$ On the other hand RA monocytes have been shown to possess enhanced cytotoxic, ${ }^{18} \mathrm{Fc}$ receptor, ${ }^{19}$ metabolic, ${ }^{20}$ and secretory activity. ${ }^{6-14} 21$

Accepted for publication 12 February 1985.

Correspondence to Dr M Seitz, Medizinische Poliklinik, Universität Heidelberg, Hospitalstr. 3, 6900 Heidelberg, West Germany.
Recently we found that monocytes from RA patients released high amounts of prostanoids ${ }^{21}$ and expressed a reduced capacity to present antigens to $T$ lymphocytes. ${ }^{22}$

The aim of the present study was twofold: (a) to 을 examine whether enhanced prostanoid release from $D$ monocytes is a specific marker of $\mathrm{RA}$; $(b)$ to correlate prostanoid release from monocytes with $N$ the inflammatory activity of RA.

We will show that an enhanced prostanoid release $N$ from monocytes is found both in the early stages of $\mathrm{W}$ untreated RA and in patients under prolonged $\underset{2}{2}$ therapy with non-steroidal anti-inflammatory drugs 0 (NSAID) or remission inducing agents. However, no correlation between prostanoid release from RA ? monocytes and systemic inflammatory activity of ${ }^{\circ}$ this disease was observed. Only patients with clinically active systemic lupus erythematosus (SLE) showed a comparable enhanced prostanoid release $\stackrel{\varnothing}{\varrho}$ from monocytes, whereas monocytes from patients $\overline{2}$ with systemic lymphatic malignancies like Hodgkin's 
disease or non-Hodgkin lymphomas and from patients with sarcoidosis showed a normal prostaglandin (PGE) and thromboxane $\left(\mathrm{TXB}_{2}\right)$ release.

Most strikingly a twofold increase of monocytes was found in the mononuclear cell fraction of RA and SLE patients, without statistical differences in the absolute amount of monocytes per millilitre blood from patients with different rheumatic diseases or normal controls.

This finding may indicate that we have separated a monocyte subpopulation with an enhanced arachidonic acid metabolism from the peripheral blood of both RA and SLE patients. The results of our study may have implications for the early diagnosis of RA and its differentiation from other inflammatory rheumatic conditions. Furthermore, our data hint at an enhanced recruitment of monocytes from the bone marrow of RA and SLE patients, with altered functional and pathogenetically relevant properties.

\section{Materials and methods}

\section{PAT I EN TS}

Fifty-five patients with active rheumatoid arthritis (RA) satisfying the American Rheumatism Association criteria for 'classical' or 'definite' were examined in this study. Twenty-five patients were seropositive and thirty were seronegative according to latex fixation and Waaler-Rose test for rheumatoid factor. Fourteen RA patients were without any therapy at the time of blood examination. Eighteen patients were being treated with gold salts and five with D-penicillamine. Forty-one patients were receiving non-steroidal anti-inflammatory drugs (NSAID). The diagnosis of definite RA in 14 untreated RA patients was established retrospectively when the disease had been present for three to six months after the first inflammatory joint manifestation. The stages of RA were determined according to Steinbrocker and included functional impairment grades I-III.

The mean duration of RA was 3.6 years (three months to eight years). Objective disease activity was measured by the number of inflamed joints, joint pains, and morning stiffness. Humoral disease activity was assessed by the erythrocyte sedimentation rate (ESR), the amount of C-reactive protein, haemoglobin, and the ratio of iron to copper in patient sera. All these clinical and laboratory data varied markedly between different RA patients.

The other groups included 25 patients with psoriatic arthritis (all on NSAID, seven on gold salts, two on D-penicillamine), 25 patients with ankylosing spondylitis mostly with large peripheral joints affected (all on NSAID only), six patients with Reiter's disease (all on NSAID only), 10 patients with acute sarcoidosis (no drugs), 15 patients with osteoarthritis (NSAID only), 10 patients with clinically active SLE (all on NSAID, two on chloroquine, five on 5-10 mg prednisone/day, four on azathioprine). The mean duration of SLE was $3 \cdot 2$ years (six months to six years), and disease activity was defined by the amount of serum antibodies to native double stranded DNA and the reduced concentration of complement serum levels. In addition, six patients with newly diagnosed Hodgkin's disease (nodular sclerosing type) stage III+IV (no drugs), five patients with non-Hodgkin lymphoma (lymphoplasmocytoid immunocytoma) stage IV, and seven patients with sarcoidosis stage II were tested.

The controls consisted of 18 healthy female and 12 male hospital employees. Medication of all patients was stopped at least two days before blood examination. In all patient groups and control individuals intercurrent disease which might interfere with monocyte function, especially infection and diabetes mellitus, was excluded.

PREPARATION OF ENRICHED MONOCYTES Heparinised venous blood was centrifuged over Ficoll-Hypaque, and the fraction containing mononuclear cells was separated and washed three times in Hanks's balanced salt solution (HBSS). Monocytes were enriched by a technique previously described in detail. ${ }^{21}$ Briefly, $20 \times 10^{6}$ mononuclear cells were suspended in $10 \mathrm{ml}$ bicarbonate-buffered RPMI 1640 medium plus 20\% heat-inactivated human $\mathrm{AB}$ serum and were seeded into Petri dishes (diameter $85 \mathrm{~mm}$ ). After incubation at $37^{\circ} \mathrm{C}$ for 60 min in an atmosphere of air plus $5 \% \quad \mathrm{CO}_{2}$ the non-adherent cells were removed by a gentle washing procedure with $\mathrm{HBSS}$ adjusted to $37^{\circ} \mathrm{C}$. The adherent monocytes were extensively washed with medium to remove the contaminating lymphoid cells, and the plates were then incubated at $4^{\circ} \mathrm{C}$ for $20 \mathrm{~min}$. Thereafter monocytes could easily be removed by flushing the monolayer with medium blown out of a syringe through a narrow injection needle.

Monocytes were centrifuged at $400 \mathrm{~g}$ for $6 \mathrm{~min}$, washed twice in HBSS and suspended in bicarbonate-buffered RPMI 1640 medium plus $10 \%$ human $\mathrm{AB}$ serum. The cells were tested for viability by trypan blue exclusion (88-93\% viable cells) and characterised as monocytes by staining for nonspecific esterase (85-92\% positive cells) according to an established method ${ }^{23}$ and by latex or carbon particle phagocytosis. ${ }^{24}$

The enriched monocyte preparation employed here after density centrifugation, plating on Petri dishes, and several washes to remove non-adherent 
cells was free of platelets when examined microscopically in stained samples, thus excluding a significant contribution of platelets to prostanoid production.

PREPARATION OF RHEUMATOID FACTOR CONTAINING IMMUNE COMPLEXES (RF-IC) $10 \mathrm{mg} / \mathrm{ml}$ (g/l) human IgG (Sigma Chemicals, München, Germany) was heated at $63^{\circ} \mathrm{C}$ for $1 \mathrm{~h}$. Heat aggregated IgG was then incubated with $10 \mathrm{ml}$ serum of RA patients with a Waaler-Rose titre of at least $1: 128$ overnight at $4^{\circ} \mathrm{C}$. Next day the cryoprecipitate was centrifuged at $15000 \mathrm{rpm}$ in a high speed centrifuge, washed three times in HBSS and dissolved in $0.9 \% \mathrm{NaCl}$. The RF-IC solution was used at a concentration of $1 \mathrm{mg} / \mathrm{ml}(\mathrm{g} / \mathrm{l})$. The end concentration in monocyte cultures was $5 \mu \mathrm{g} / \mathrm{ml}$ (mg/l), which proved to be optimal for stimulation of prostanoid release in dose response experiments.

\section{DETERMINATION OF PROSTANOIDS}

PGE and $\mathrm{TXB}_{2}$ in the cell-free culture supernatant were measured by radioimmunoassay as described previously, ${ }^{25}$ with a rabbit antibody raised against $\mathrm{PGE}_{1}$ which completely cross reacted with $\mathrm{PGE}_{2}$. Values given are therefore expressed as PGE without subclass specification. $\mathrm{TXB}_{2}$ release was also determined by radioimmunoassay with highly specific antibodies which were generated in rabbits $\Rightarrow$ as outlined previously. ${ }^{26}$ These antisera cross $\stackrel{\vec{\rho}}{\stackrel{9}{\circ}}$ reacted less than $0.5 \%$ with other arachidonic acid derivatives.

CELL CULTURES FOR DETERMINATION OF PROSTANOID RELEASE

Enriched monocytes were cultured in bicarbonate- $\vec{O}$ buffered RPMI 1640 medium supplemented with $\mathrm{L}-\overrightarrow{\vec{H}}$ glutamine, penicillin $(100 \mathrm{U} / \mathrm{ml})$, streptomycin $(100 \hat{\omega}$ $\mu \mathrm{g} / \mathrm{ml}(\mathrm{mg} / \mathrm{l}))$, and $10 \%$ heat-inactivated human AB serum. Cells were seeded in flat-bottom micro-? titre plates at a concentration of $1 \times 10^{5} / 0 \cdot 2 \mathrm{ml}$. Lipolysaccharide (LPS) from Escherichia coli and $v$ various drugs or supplements were added directly to $\vec{\omega}$ the wells and the final volume of the wells was adjusted to $0.25 \mathrm{ml}$. Cell cultures were incubated at $37^{\circ} \mathrm{C}$ in an atmosphere of air plus $5 \% \mathrm{CO}_{2}$, for $\vec{a} \vec{c}$ total period of $24 \mathrm{~h}$. After this $0 \cdot 15 \mathrm{ml}$ culture supernatant was removed from each well for prostanoid determination.

\section{DATA ANALYS IS}

Prostanoid release from monocytes of all patients and control subjects was compared according to the

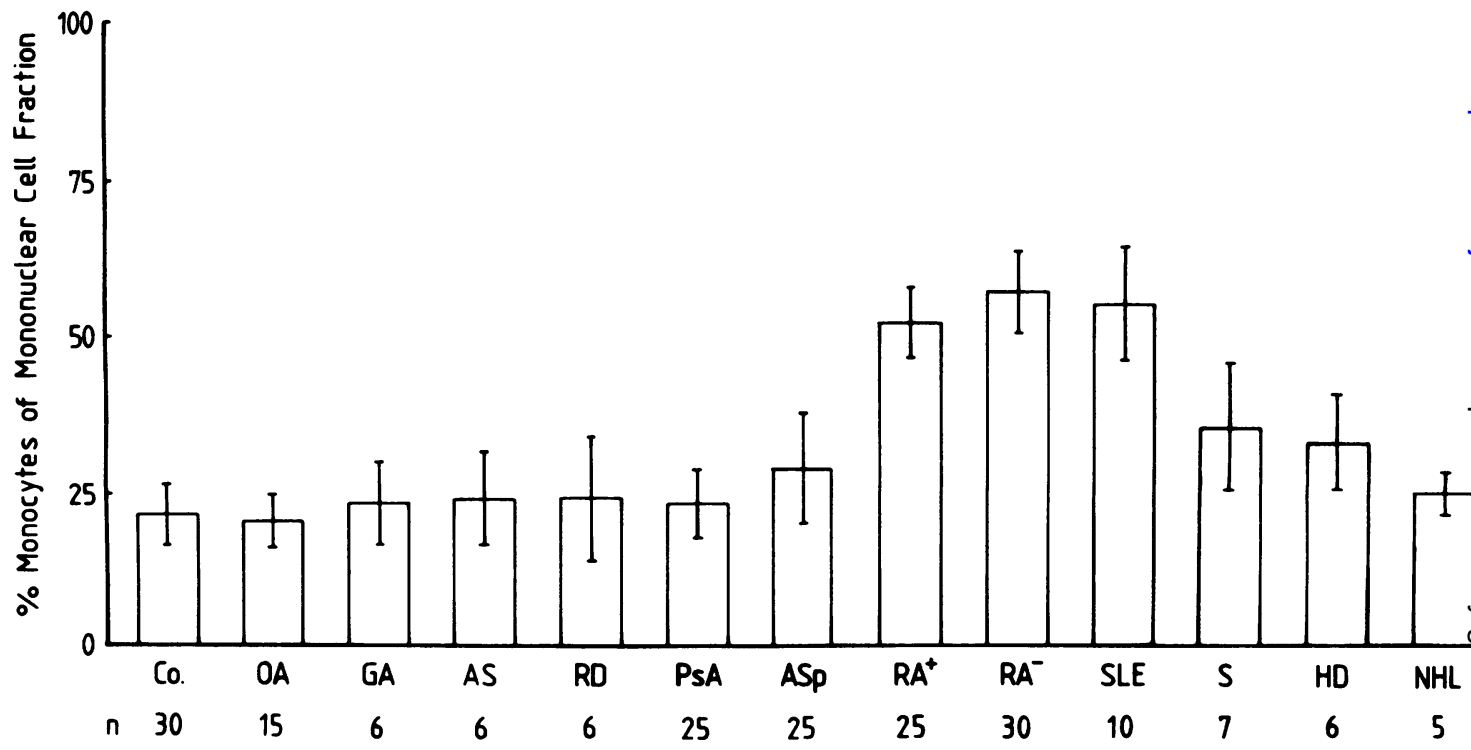

Fig. 1 Amount of non-specific esterase-positive monocytes in the mononuclear cell fraction after Ficoll-Hypaque centrifugation. Values shown are the mean percentage of monocytes $\pm S D$ among the mononuclear cells of healthy controls $(C o)$, patients with osteoarthritis $(O A)$, gouty arthritis $(G A)$, acute sarcoidosis $(A S)$, Reiter's disease (RD), psoriatic arthritis (PsA), ankylosing spondylitis ( $A S P)$, seronegative rheumatoid arthritis $\left(R A^{-}\right)$, seropositive rheumatoid arthritis $\left(R A^{+}\right)$, systemic lupus erythematosus (SLE), sarcoidosis (S), Hodgkin's disease (HD), and non-Hodgkin lymphoma $(N H L)$. 

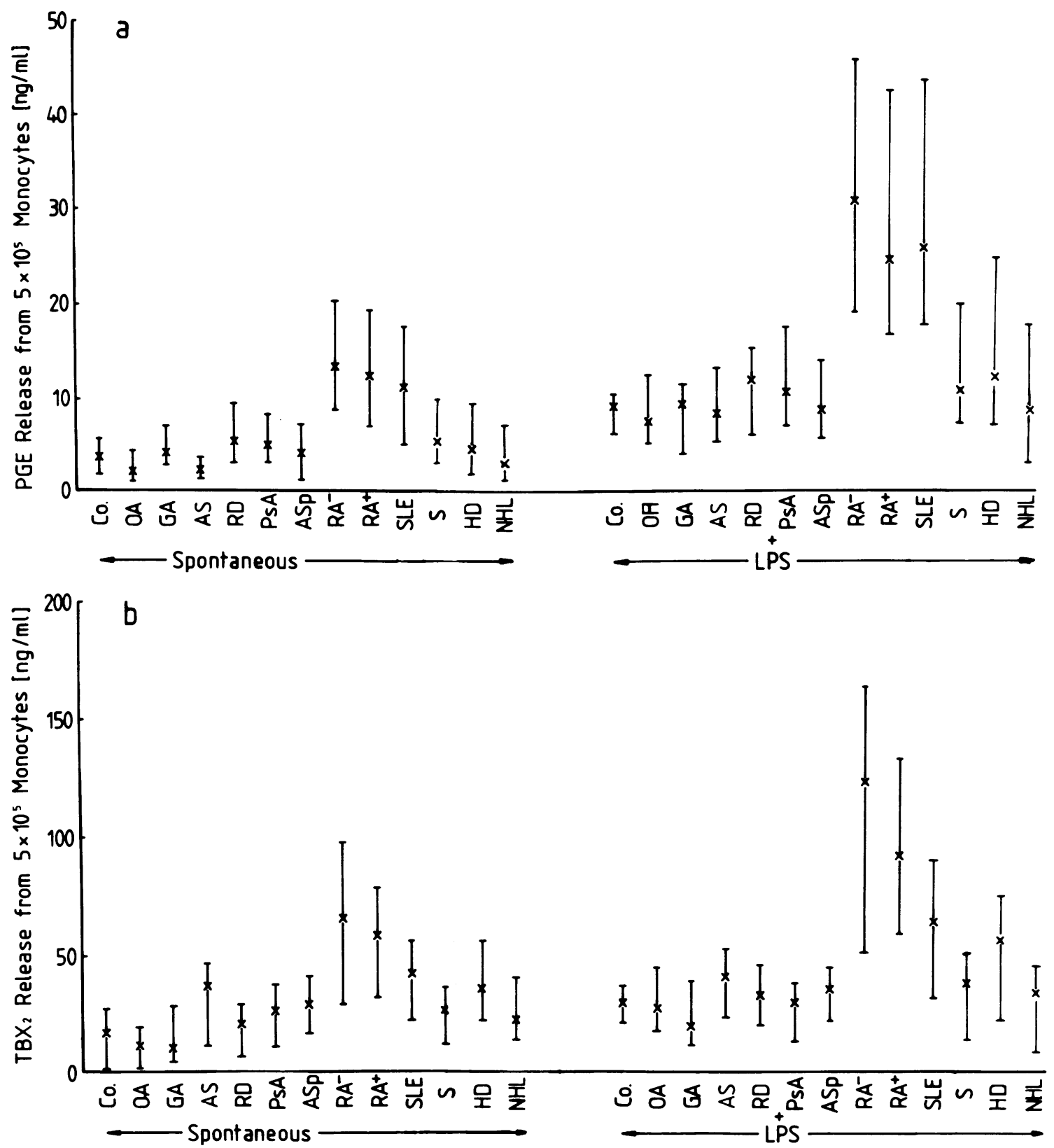

Fig. 2 Prostanoid release from monocytes of healthy controls and patients with different rheumatic disorders. Monocytes of controls and patients with osteoarthritis $(O A)$, gouty arthritis $(G A)$, acute sarcoidosis $(A S)$, Reiter's disease $(R D)$, psoriatic arthritis ( $P S A)$, ankylosing spondylitis ( $A S p)$, seronegative rheumatoid arthritis $\left(R_{A^{-}}\right)$, seropositive rheumatoid arthritis $\left(R A^{+}\right)$, systemic lupus erythematosus $(S L E)$, sarcoidosis $(S)$, Hodgkin's disease (HD), and non-Hodgkin lymphoma (NHL) were incubated for $24 \mathrm{~h}$ without stimuli (spontaneous) or with LPS (10 $\mu \mathrm{g} / \mathrm{ml}(\mathrm{mg} / \mathrm{l}))$. (a) PGE ana (b) $T X B_{2}$ were determined by radioimmunoassay in the cell-free culture supernatant. Values represent prostanoids (ng/ml $(\mu \mathrm{g} / \mathrm{l}))$ released from $5 \times 10^{5}$ monocytes during $24 \mathrm{~h}$ of incubation. Shown are the mean and the upper and lower confidence limits. Statistical analysis performed with the Dunn test showed a significant difference $(\alpha=0.05)$ between the group of seronegative and seropositive RA patients, SLE patients, and patients with other rheumatic and non-rheumatic diseases or healthy control individuals. 
Kruskal-Wallis test, with subsequent multiple comparisons according to Dunn. ${ }^{27}$

D R U G S

Various additives were used in the following concentrations: lipopolysaccharide from E. coli 0127 (10 $\mu \mathrm{g} / \mathrm{ml}(\mathrm{mg} / \mathrm{l})$; Gibco, Glasgow, UK), $\gamma$-interferon (50 IU/ml of a DNA recombinant, Thomae, Biberach, Germany), and interleukin 2 (1:8 diluted; Biotest, Frankfurt, Germany).

\section{Results}

AMOUNT OF MONOCYTES IN THE

MONONUCLEAR FRACTION (Fig. 1)

There were no statistical differences in the absolute amount of monocytes per millilitre of blood from patients with different rheumatic diseases or healthy control individuals (data not shown). However, when the mononuclear cell fraction after FicollHypaque centrifugation was examined for the number of monocytes, patients with RA and active SLE showed a significantly higher number of non-specific esterase-positive monocytes than patients with psoriatic arthritis (PsA), ankylosing spondylitis (ASp), Reiter's disease (RD), acute sarcoidosis (AS), gouty arthritis (GA), osteoarthritis (OA), Hodgkin's disease (HD), non-Hodgkin lymphomas (NHL), sarcoidosis $(\mathrm{S})$, or healthy control subjects $(\mathrm{Co})$. These data are shown in Fig. 1.

\section{PROSTANOID RELEASE FROM MONOCYTES}

(Fig. 2b, Table 1)

Enriched monocytes from patients with seropositive and seronegative RA, psoriatric arthritis, Reiter's syndrome, ankylosing spondylitis, acute sarcoidosis, systemic lupus erythematosus, gouty arthritis, osteoarthritis, sarcoidosis, Hodgkin's disease, nonHodgkin lymphoma, and healthy control subjects were cultured in vitro for $24 \mathrm{~h}$. Significantly higher amounts of PGE and $\mathrm{TXB}_{2}$ were spontaneously released only from monocytes of both $R A$ patient groups and patients with active SLE. A much higher release was noted when monocytes of these patients were stimulated by lipopolysaccharide from $E$. coli (LPS), which proved to be a good stimulator of arachidonic acid metabolism of monocytes. ${ }^{21}$

In contrast, monocytes from patients with other inflammatory or degenerative rheumatic diseases, patients with Hodgkin's disease, non-Hodgkin lymphoma, and sarcoidosis or healthy controls were much less reactive to stimulation with LPS. A similar pattern of PGE and $\mathrm{TXB}_{2}$ release emerged when monocytes were stimulated with rheumatoid factor containing immune complexes (RF-IC), $\gamma$ interferon $(\gamma$-IF), or interleukin 2 (IL 2). The 

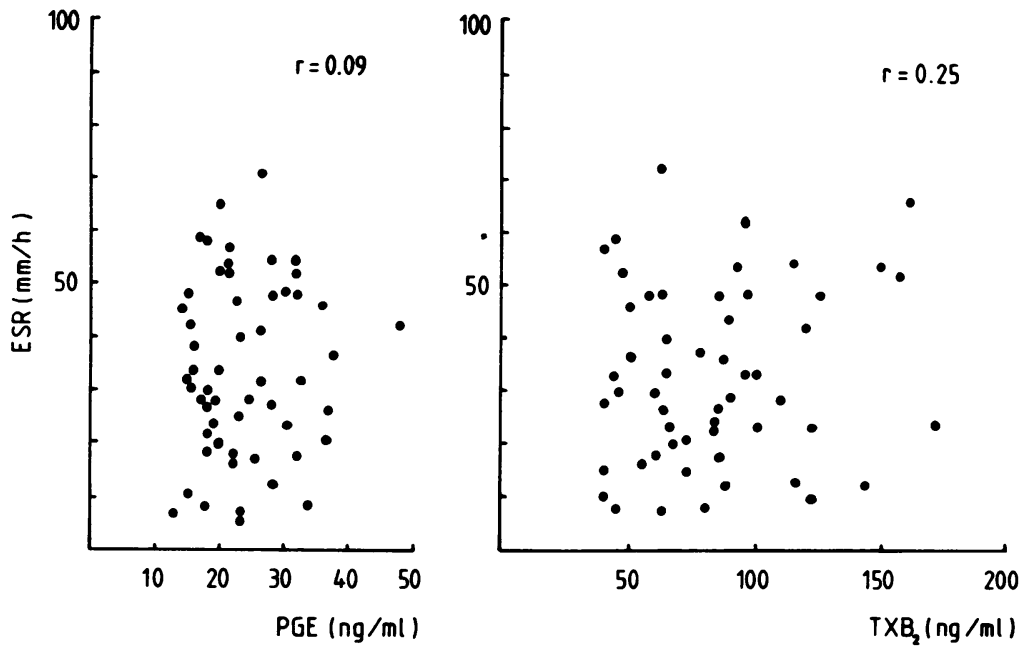

Fig. 3 Correlation of prostanoid release ( $P G E$ and $T X B_{2}, n g / m l$ $(\mu \mathrm{g} / \mathrm{l}))$ from monocytes of $55 \mathrm{RA}$ patients (seronegative and seropositive) after stimulation with LPS $(10 \mu \mathrm{g} / \mathrm{ml}(\mathrm{mg} / \mathrm{ll}))$ to the erythrocyte sedimentation rate $(E S R ; m m / h)$. Statistical evaluation resulted in two correlation coefficients $(r=0.09$ for $P G E ; r=0.25$ for $T X B_{2}$ ).

absolute amount of prostanoids detected in the culture medium after $\gamma$-IF and IL 2 stimulation, however, was not statistically different from that of unstimulated control cultures.

PROSTANOID RELEASE AND INFLAMMATORY ACTIVITY OF RA (Fig. 3)

Monocytes from RA patients with quite different inflammatory activities and stages of disease were incubated for $24 \mathrm{~h}$ as described above. PGE and $\mathrm{TXB}_{2}$ release in the culture supernatant was correlated with the ESR, which was used as reflecting systemic inflammatory activity. No correlation $\left(r=0.09\right.$ for PGE; $r=0.25$ for $\left.\mathrm{TXB}_{2}\right)$ between prostanoid release from monocytes and systemic inflammatory activity of individual RA patients was observed.

\section{Discussion}

There is evidence that proliferating synovial cells and monocyte-derived macrophages in the perivascular infiltrates of the synovial membrane of RA patients may amplify the inflammatory process and induce juxta-articular bone resorption by release of arachidonic acid (AA) products, especially $\mathrm{PGE}_{2}$. This can be concluded from three main findings: First, clinical experience shows that treatment with non-steroidal anti-inflammatory drugs, usually inhibitors of the cyclo-oxygenase pathway of arachidonic acid metabolism, decreases inflammatory symptoms. Secondly, previous studies have shown that cells of the proliferating synovium lacking conventional macrophage markers release excessive amounts of $\mathrm{PGE}_{2}$ when kept in culture. ${ }^{67}$ Thirdly, $\mathrm{PGE}_{2}$ proved to be an essential cofactor to an enhanced production of osteoclast activating factor. ${ }^{28}{ }^{29} \mathrm{PGE}_{2}$ synthesis in the synovial membrane may be stimulated by immunoglobulins with an intact Fc portion, ${ }^{30}{ }^{31}$ collagens II+III, ${ }^{32}$ and a monocyte-derived factor which appears to be identical with interleukin $1 .{ }^{13}$

Although these findings clearly hint at some type of disregulation in arachidonic acid metabolism in cells present in the synovial space, the underlying mechanism which leads to an enhanced prostanoid release remains to be elucidated. On the assumption that at least some prostanoid producing synovial cells are derived from blood precursors, namely monocytes, we examined blood monocytes, speculating that a basic defect might already be detectable in these cells. Although we recently showed an enhanced prostanoid release from blood monocytes of RA patients, in the present study we tried to clarify the question of whether an enhanced prostanoid release represents a characteristic property of RA monocytes or whether this finding is more a nonspecific epiphenomenon which can also be detected in other chronic inflammatory rheumatic and nonrheumatic diseases or in systemic lymphatic malignancies.

The present study shows that purified blood monocytes of both RA patients (seropositive and seronegative) and patients with clinically active SLE released higher amounts of $\mathrm{PGE}$ and $\mathrm{TBX}_{2}$ than monocytes from patients with other inflammatory joint diseases, osteoarthritis, Hodgkin's disease, non-Hodgkin lymphoma, sarcoidosis, or from 
healthy control individuals (Fig. 2). In contrast, monocytes from patients with inactive SLE (data not shown) released normal amounts of prostanoids.

Most notably, monocytes from RA patients both with early stage or mild inflammatory activity and those with prolonged inflammatory activity produced enhanced, although differing, amounts of $\mathrm{PGE}$ and $\mathrm{TXB}_{2}$ (all patients are included within the two RA groups).

A rather critical problem in studying arachidonic acid metabolism in leucocytes from such patients stems from the concurrent use of antirheumatic therapy (NSAID alone or in combination with remission inducing drugs like gold or D-penicillamine). Especially since NSAID are known inhibitors of the cyclo-oxygenase pathway of AA metabolism. However, all of the patients examined in this study were free of antirheumatic therapy for at least two days. Moreover, an enhanced prostanoid release occurred even from monocytes of early diagnosed and initially untreated RA patients, thus making a therapy induced effect, possibly in the sense of a rebound phenomenon after drug withdrawal, rather unlikely.

The important question to emerge is whether prostanoid release from monocytes is correlated to drug effects or to inflammatory activity. To approach that problem we tried to correlate prostanoid release with systemic inflammatory activity. No correlation could be found between prostanoid release and systemic inflammatory activity as measured by the ESR in the group of RA patients (Fig. 3). In the light of these findings we conclude that enhanced prostanoid release from monocytes does not merely reflect high inflammatory activity of RA but can also be detected in mild and less active forms of the disease. It is certainly conceivable that RA monocytes, after further differentiation into macrophages and related cells (synovial ' $A$ ' cells?) in the joints express an even stronger capacity for an enhanced prostanoid release. After appropriate stimulation this may lead to excessive prostanoid release in the synovial membrane and to subsequent bone resorption, probably by modulating functions of other immune competent cells or osteoclasts.

At present we can only conclude from the enhanced numbers of monocytes in the mononuclear cell fraction of RA and SLE patients (Fig. 1) that a subpopulation of monocytes with a somewhat 'stimulated' AA metabolism exists in these two rheumatic disorders. Our information is still insufficient to allow us to distinguish between the possibilities that enhanced AA conversion results from an inherent instability of phospholipid metabolism or that some unknown mediators, infective agents or stimulated cells, induce RA and SLE monocytes to more rapid prostanoid release. Assuming that mediators with known monocyte stimulating prop erties, e.g., immune complexes, interferons, ands interleukin 2, may be causative agents, we haveo performed corresponding stimulation experiments.흐

We showed that only rheumatoid factor contain- $\frac{-5}{5}$ ing immune complexes (RF-IC) and to a lesser ${ }^{\mathbb{D}}$ extent $\gamma$-interferon or interleukin 2 induced prostanoid release from monocytes both of RA patients and normal controls. The absolute amount of $\mathrm{PGE}^{\circ}$ and $\mathrm{TXB}_{2}$ release, however, was again much more $\vec{\omega}$ pronounced in RA patients but considerably lowero than after LPS stimulation (Table 1).

Finally, there remains the notable finding that enhanced prostanoid release occurred only from patients with RA and active SLE, two diseases ini which the immune system is involved. In order tom confirm the specificity of our findings an examina-o tion of monocyte AA metabolism in other immunocritical conditions like Hodgkin's disease, non- $-\subset$ Hodgkin lymphomas, or sarcoidosis was performed, and no striking differences from normal controk individuals were found.

In conclusion our data hint at an essentiab pathogenic role of prostanoids in RA, which mays also have implications for the early diagnosis of RA and its differentiation from other inflammatory rheumatic diseases.

We thank Miss B Gaber for her excellent technical assistance. This work is supported by DFG Se 372/2-2.

\section{References}

1 Janossy G, Duke O, Poulter L W, Panayi G, Bofill Mdे Goldstein G. Rheumatoid arthritis; a disease of T-lymphocyte macrophage immunoregulations. Lancet 1981; i: 839-42.

2 Poulter L W, Duke O, Hobbs S, Janossy G, Panayi Gב Histochemical discrimination of HLA-DR positive cell popula? tions in the normal and arthritic synovial lining. Clin Exp Immunol 1982; 48: 381-8.

3 Ishikawa $H$, Ziff $M$. Electron microscopic observations of음 immunoreactive cells in the rheumatoid synovial membrane. Arthritis Rheum 1976; 19: 1-14.

4 Kobayashi I, Ziff M. Electron microscopic studies of the cartilage-pannus junction in rheumatoid arthritis. Arthritis Rheum 1975; 18: 475-83.

5 Goldenberg D L. Cohen A S. Synovial membrane histopathol-N ogy in the differential diagnosis of rheumatoid arthritis, gout $N$ pseudogout, systemic lupus erythematosus, infectious arthritis $\omega$ and degenerative joint disease. Medicine (Baltimore) 1978; 57: 239-52.

6 Dayer J-M, Krane S M, Russel R G G, Robinson D R. Production of collagenase and prostaglandins by isolatedes adherent rheumatoid synovial cells. Proc Natl Acad Sci USA ${ }^{+}$ 1976; 73: 945-9.

7 Dayer J-M, Russel R G G, Krane S M. Collagenase production음 by rheumatoid synovial cells: stimulation by a human lymphocyte factor. Science 1977; 195: 181-3.

8 De Ceulaer C, Papazoglou S, Whaley K. Increased biosynthesis of complement components by cultured monocytes, synovialo fluid macrophages and synovial membrane cells from patients with rheumatoid arthritis. Immunology 1980; 41: 37-43. 
9 Morley J. Prostaglandins and lymphokines in arthritis. Prostaglandins 1974; 8: 315-26.

10 Robinson D R, Levine L. Prostaglandin concentrations in synovial fluid in rheumatic diseases; actions of indomethacin and aspirin. In: Robinson H J, Vane J R, eds. Prostaglandins synthetase inhibitors. New York: Raven, 1974; 223-8.

11 Sturge R A, Yates D B, Gordon D, et al. Prostaglandin production in arthritis. Ann Rheum Dis 1978; 37: 315-20.

12 Mizel S B, Dayer J-M, Krane S M, Stephan E, Mergenhagen E. Stimulation of rheumatoid synovial cell collagenase and prostaglandin production by partially purified lymphocyte activating factor (interleukin 1). Proc Natl Acad Sci USA 1981; 78: 2474-7.

13 Dayer J-M, Stephenson M L, Schmidt E, Karge W, Krane S M. Purification of a factor from human blood monocytemacrophages which stimulates the production of collagenase and prostaglandin $E_{2}$ by cells cultured from rheumatoid synovial tissues. FEBS Lett 1981; 124: 253-6.

14 Robinson D R, Tashijian A H, Levine L. Prostaglandinstimulated bone resorption by rheumatoid synovia. J Clin Invest 1975; 56: 1181-8.

15 Williams B D, Lockwood C M, Pussell B A, Cotton C. Defective reticuloendothelial system function in rheumatoid arthritis. Lancet 1979; i: 1311-4.

16 Hurst N P, Nuki G, Wallington T. Functional defects of monocytes $\mathrm{C} 3 \mathrm{~b}$ receptor-mediated phagocytosis in rheumatoid arthritis (RA): evidence for an association with the appearance of a circulating population of non-specific esterase-negative mononuclear phagocytes. Ann Rheum Dis 1983; 42: 487-93.

17 Bar-Eli M, Ehrenfeld M, Litvin Y, Gaillily R. Monocyte function in rheumatoid arthritis. Scand J Rheumatol 1980; 9: 17-23.

18 Waytz P H, Douglas S D. Increased antibody-dependent cellmediated cytotoxicity by monocytes from patients with rheumatoid arthritis. Arthritis Rheum 1979; 22: 490-4.

19 Møller Rasmussen J, Brandslund I, Rasmussen G G, Svehag S-E. Increased number of IgG Fc-receptors on monocyteenriched peripheral blood leucocytes from patients with rheumatoid arthritis. Scand J Immunol 1982; 16: 279-85.

20 Kay N E, Douglas S D. Monocyte metabolic activation in patients with rheumatoid arthritis. Proc Soc Exp Biol Med 1979; 161: $303-6$.
21 Seitz M, Deimann W, Gram N, Hunstein W, Gemsa D. Characterization of blood mononuclear cells of rheumatoid arthritis patients. I. Depressed lymphocyte proliferation and enhanced prostanoid release from monocytes. Clin Immunol Immunopathol 1982; 25: 405-16.

22 Seitz M, Vogt $P$, Müller W, Hunstein W, Gemsa D. Characterization of blood mononuclear cells of rheumatoid arthritis patients. II. Depressed PPD presentation by monocytes to T-lymphocytes. Clin Immunol Immunopathol 1983; 29: 242-53.

23 Koski J R, Poplack D G, Blaese R M. A nonspecific esterase stain for the identification of monocytes and macrophages. In: Bloom C B R, David J R, eds. In vitro methods in cell mediated and tumor immunity. New York: Academic Press, 1976; 359.

24 Gemsa D, Woo C H, Fudenberg H H, Schmid R. Erythrocyte catabolism by macrophages in vitro. The effect of hydrocortisone on erythrophagocytosis and on the induction of heme oxygenase. J Clin Invest 1973; 52: 812-22.

25 Gemsa D, Seitz M, Kramer W, Till G, Resch K. The effects of phagocytosis, dextrane sulfate and cell damage on $\mathrm{PGE}_{1}$ sensitivity and $\mathrm{PGE}_{1}$ production of macrophages. J Immunol 1978; 120: 1187-94.

26 Grimm W, Seitz M, Kirchner H, Gemsa D. Prostaglandin synthesis in spleen cell cultures of mice injected with corynebacterium pavoum. Cell Immunol 1978; 40: 419-26.

27 Weber E. Technical Report DKFZ 1980.

28 Yoneda T, Munday G R. Monocytes regulate osteoclastactivating factor production by releasing prostaglandins. $J$ Exp Med 1979; 150: 338-50.

29 Dominguez J H, Mundy G R. Monocytes mediate osteoclastic bone resorption by prostaglandins production. Calcif Tissue Int 1980; 31: 29-34.

30 Passwell J H, Dayer J-M, Merler E. Increased prostaglandin production by human monocytes after membrane receptor activation. J Immunol 1979; 123: 115-20.

31 Dayer J-M, Passwell J H, Schneeberger E E, Krane S M. Interactions among rheumatoid synovial cells and monocytemacrophages: production of collagenase-stimulating factor by human monocytes exposed to concanavalin A or immunoglobulin Fc fragments. $J$ Immunol 1980 124: 1712-20.

32 Dayer J-M, Trentham D E, David J R, Krane S M. Collagens stimulate the production of mononuclear cell factor (MCF) and prostaglandins $\left(\mathrm{PGE}_{2}\right)$ by human monocytes. Trans Assoc Am Physicians 1980; 93: 326-35. 